\title{
X.-THERAPEUTICAL NOTE.
}

By J. Crawford Renton, M.B., Etc., Glasgow.

THE great advantages derived from opium and its derivatives are sometimes materially interfered with by the severe and annoying sickness which often follows their administration.

The recommendation of Sir Robert Christison to give a little brandy before the patient is allowed to leave his or her bed answers the desired effect sometimes, but in several cases lately where we have had to use opium pretty freely the sickness has been very distressing. We accordingly suggested that after each dose 15 grains of bromide of potassium should be taken, and uniformly the result has been a cessation of the annoying symptom, and prevention of it for the future. One patient informed us that she had never taken opium before without having severe sickness afterwards.

\section{嗮e foretos.}

1.-The Successful Treatment of Internal Aneurisi by ConsolidaTION OF tHe Contents of tHe SAC. By Jolliffe TuFnell, F.R.C.S.I., President of the Royal College of Surgeons in Ireland. London: J. \& A. Churchill. 2nd Edition. 1875. pp. 71.

OF late years our knowledge of the treatment of internal aneurisms has made very rapid strides, so much so that this class of diseases may safely be transferred from the list of incurable to that of curable. We can now resort, with good prospects of success, to galvano-puncture: some think that the same remark is applicable to the treatment by means of iodide of potassium; and a perusal of Mr Tufnell's pamphlet leads to the conclusion that we may also look for cures by the adoption of the measures recommended by him. These have, in addition, the merit of great simplicity, and consist of absolute repose for a period of two or three months, and a very restricted diet. "The diet, under ordinary circumstances, must be confined to three meals, served at regular intervals, and restricted to the following in kind and in amount, viz.:-For breakfast, two ounces of white bread and butter, with two ounces of cocoa or milk. For dinner, three 
ounces of broiled or boiled meat, with three ounces of potatoes or bread, and four ounces of water or light claret. For supper, two ounces of bread and butter, and two ounces of milk or tea, making in the aggregate ten ounces of solid and eight ounces of fluid food in the twenty-four hours, and no more." Details are also given as to the arrangement of the bed upon which the patient lies (at p. 64), and as to the use of remedial agents to meet special symptoms and complications (at p. 66). The pamphlet is adorned by several very beautiful coloured illustrations, and many cases are quoted in which, under the above treatment, recoveries took place. Here is one of them:-

"A hackney carman, named Doyle, aged 35, was admitted into the City of Dublin Hospital, for an aneurism of the abdominal aorta as large as an orange. He was placed under restricted diet and perfect rest in the horizontal position for three months, being allowed only 8 ounces of solid food, and 6 ounces of fluid during the twenty-four hours. The tumour soon became partially solid, so that when grasped, it imparted to the hand the idea of considerable density. The recumbent position was, however, maintained for the period stated. He was then allowed to leave his bed, and three weeks afterwards quitted the hospital, shortly subsequent to which he resumed his occupation. At the end of eighteen months I met him plying at a railway station, and hired him for the journey I was going upon. He told me that he had been 'all right' ever since he left the hospital, and was perfectly able to do all his work, with the exception of lifting a bucketful of water, which he found great difficulty in effecting, from inability to straighten his back. He stated that he never felt any inconvenience from driving, excepting when the car gave a jolt in passing over a crossing. Three years afterwards (that is, fouranda half years from the time of being under treatment), I saw him again at his stand, and he told me he had been driving uninterruptedly ever since. This man died subsequently from the effects of an accident."

In conclusion, we can most cordially recommend the perusal of this brochure to those who are interested in the treatment of internal aneurism, for it contains very valuable information, pleasantly told, and in small bulk; and we may add that, having had the pleasure of inspecting Mr Tufnell's preparations in Dublin, we can endorse that which he says with regard to them. 